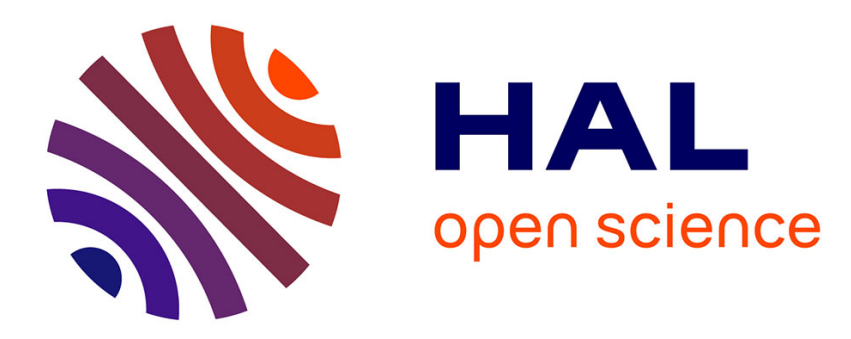

\title{
Rational behaviour, Risk aversion, High stakes for society
}

André de Palma

\section{To cite this version:}

André de Palma. Rational behaviour, Risk aversion, High stakes for society. 2008. hal-00349462

\section{HAL Id: hal-00349462 \\ https://hal.science/hal-00349462}

Preprint submitted on 31 Dec 2008

HAL is a multi-disciplinary open access archive for the deposit and dissemination of scientific research documents, whether they are published or not. The documents may come from teaching and research institutions in France or abroad, or from public or private research centers.
L'archive ouverte pluridisciplinaire HAL, est destinée au dépôt et à la diffusion de documents scientifiques de niveau recherche, publiés ou non, émanant des établissements d'enseignement et de recherche français ou étrangers, des laboratoires publics ou privés. 


\title{
ECOLE POLYTECHNIQUE
}

CENTRE NATIONAL DE LA RECHERCHE SCIENTIFIQUE

\section{RATIONAL BEHAVIOUR, RISK AVERSION HIGH STAKES FOR SOCIETY}

\author{
André de PALMA
}

October 2008

Cahier $n^{\circ} 2008-20$

\section{DEPARTEMENT D'ECONOMIE}

Route de Saclay

91128 PALAISEAU CEDEX

(33) 169333033

http://www.enseignement.polytechnique.fr/economie/

mailto:chantal.poujouly@polytechnique.edu 


\title{
RATIONAL BEHAVIOUR, RISK AVERSION HIGH STAKES FOR SOCIETY ${ }^{1}$
}

\author{
André de PALMA ${ }^{2}$
}

October 2008

Cahier $n^{\circ}$ 2008-20

JTRC - OECD/ITF

Round Table

Security, Risk Perception and Cost-Benefit Analysis

Paris, 11-12 December 2008

Key Words : $\quad$ Risk, uncertainty, home security, expected utility, non-expected utility, OECD

\footnotetext{
${ }^{1}$ My thanks to Serge Pahaut for our many fruitful discussions together over the past few years. Nathalie Picard and Jean Picard submitted useful suggestions for improving the quality and readability of this paper. Lastly, Kurt van Dender also helped me to improve its presentation.

${ }^{2}$ Department of Economics Ecole Polytechnique, ENS Cachan, Member of the Institut Universitaire de France
} 
... I blame them for having made ... a choice ...

The true course is not to wager at all ...

...but you must wager...You are embarked.

Which will you choose then?

Pascal, Thoughts

(Lafuma 418, Brunschvicg 233)

\section{Introduction $^{2}$}

Certain areas related to the topics under discussion here lie outside my field; for instance the evaluation of risk assessment and security deficiencies in the transport sector. What has convinced me of the importance of this subject are a few very general conclusions, indeed I would say, impressions, that I have drawn from the truly remarkable development of our powers to analyse the risk decision-making process over some years now.

In this paper, the term "lack of safety" is often used with reference to the management of risks arising from intentionally malicious acts ${ }^{3}$. The costs of security in this sense of the term are an element of every transport budget today. In addition to the costs of prevention, surveillance and forecasting, the costs of the potential damages arising from such acts will also have to be taken into consideration from this point onwards.

The events of 11 September 2001, which accelerated this trend, should suffice to convince us that, from now on, the consequences of such damages will be on a scale comparable to the costs of war. Some authors have taken issue with the idea that there would exist some scale chasm between these two types of phenomena. Actually, the figures for wars connected with terrorism today are reported to be somewhere well in excess of millions of billions of dollars. This is what is to be gathered from General Haig's response (2003) that terrorism is now a branch of warfare. In a sense that we have yet to define, these are strategic decisions. The criteria which, in the eyes of the US Government, linked this attack to the wars that followed have actually more to do with retaliation than with simply estimating the consequence of the costs and benefits of a prevention policy, where these can be calculated.

Hence, the additional expenditures incurred in many areas since the events of 11 September 2001 are not purely consequences that are more or less costly or more or less acceptable. That is because they are linked to the part played by these events in exposing vulnerabilities that were, and still are, largely underestimated

\footnotetext{
${ }^{2}$ My thanks to Serge Pahaut for our many fruitful discussions together over the past few years. Nathalie Picard and Jean Picard submitted useful suggestions for improving the quality and readability of this paper. Lastly, Kurt van Dender also helped me to improve its presentation.

${ }^{3}$ The lessons of history and anthropology warn us that we had best not draw the rash conclusion that any two things are linked unless they show a link everywhere they occur. As a concept, security actually has its roots deep in the prehistory of law. Whatever the interpretation proposed, in many civilisations it harks back to some solemnised form of public ritualised practice. Here, one should at least note that the different mutations that this family of practices has gone through extend to much more than the socially guaranteed recognition of individual entitlement as it relates to the power to buy and sell freely. In other words, while the object at stake often attracts enemies, it does not necessarily have an owner.
} 
— and to a desire to retaliate. The fact is that the logic of deterrence - a field in which the military man is more at ease than the economist - can simply not be reduced to the calculation of prevention and surveillance costs.

Viewed in this light, it is easy to see why economists do not feel very able to contribute to the definition of deterrence policies. Nevertheless, what economists can do is to approach the problem from the other end. Instead of calculations as to the logic of the decision, they can endeavour to propose an estimate of the various costs. This was what started off discussions on the costs of the US War in Iraq in budgetary terms: with their estimate of USD 3000 billion, Stiglitz and Bilmes (2008) prompted a substantial revision of previously accepted estimates of these costs ${ }^{4}$.

This brings us up against the limitations of cost-benefits analysis, as Stiglitz concluded in a bid to counter claims that he had neglected ${ }^{5}$ the latter approach: costs were very substantially higher than had been stated by US political leaders. More importantly, with reference to benefits, Stiglitz said plainly that there were none that he could see. As we are reminded by the work of the founders of prospective analysis in economics — of whom we will say more below - the strategic approach does more than simply extend extrapolation calculations: it complements them.

\section{Cost-benefit and prospective analysis}

The aim of cost-benefit analysis is to evaluate the outcomes of a given project. Choices may be absolute (a proposed project will either be selected or not) or relative: there are two competing projects and decisionmakers must determine which alternative they consider most appropriate.

The work of planning and prospective analysis — some fine exercises of which were seen in the last century - requires that the implied relationships be handled by a less binary process. This means that there will be several series of decisions to take: which projects for which programme, when and how their execution can be slotted into a job schedule, which methods of finance seem appropriate, which supporting measures will be required, to mention but a few. This is very far from a straightforward all-or-nothing answer.

By now, we are well used to reading that putting each programme in place requires the co-ordination of a series of sub-programmes and the need for cross-transactions with other programmes. The $20^{\text {th }}$ century talked a great deal about priority ranking in this respect, a technique that ensures that nothing is missed out.

Over the past few decades we have learned to associate various sets of risks with these programmes: risks associated with fluctuations in demand, sudden changes in the costs of production factors, setbacks in completion time and the risk of seeing programmes appear which could fully or partly replace those on which firm decisions have already been taken, etc.

These risks are themselves associated with others: the vagaries of the economic cycle, more or less sudden shifts in the price of raw materials, hitches in the course of the project. The list is endless, we know, but in times of escalating hostilities, any omission will only too readily be seen — with the virtue of hindsightas criminal negligence or sheer stupidity, even when the omission, whatever it was, had genuinely been said insignificant at the time.

\footnotetext{
${ }^{4}$ For reference, the amounts are of the order of the annual GDP of the US, which is currently around USD 15000 billion.

${ }^{5}$ See the discussions on this idea in Viscusi (2003).
} 
Here, we have learned to identify some risks that are foreseeable and quantifiable and some that are foreseeable but difficult to evaluate. Lastly, as evaluation methods progress, it often seems with hindsight that other risks should have been included in an evaluation, but were simply omitted.

For instance, it has been axiomatic for centuries now that the construction costs of large-scale infrastructure projects are frequently revised upwards in the course of the project. One particular difficulty - and every error here is costly - is to ensure proper synchronisation of the work of several teams operating together: a construction site, by definition, is not like a routine production-line operation. Therefore, it is rather difficult to see how prospective cost-benefit analysis studies can quietly ignore these risks. Moreover, once built, the infrastructure will inevitably face greater intermodal competition.

Clearly, these observations are well within the grasp of any first-year student who has just signed up for an industrial economics course. They have also entered into the folklore of observers of collective decisionmaking ${ }^{6}$. So as not to make these — suddenly more human- decision-makers look more fallible than they actually are it is only reasonable to make allowances, too, for the host of different agents involved in this kind of large-scale investment project.

Something else that we have known for centuries is that business banks are not necessarily averse to cost increases in construction programmes under way. After all, their primary function in this context is lending - not repaying. Any inconsistencies that become obvious after the event stem largely from forgetting, when we look back, that the mutual interests of the principals only ever partially coincided.

In these times of widespread crisis, the issue will not be if or how the entrepreneurs in question could or should have done more to meet specifications, often drafted after the fact, once the fatal failure has been noticed. Rather, it will be whether we can afford the time to take on board these consequences, which at one time were genuinely negligible, but later turned out to be a factor in the accelerated changes that our world is now going through.

To put it simply, assuming that whatever issue challenges us is one that is identifiable and measurable, then the new economics of risk management may well not be of any great help. For example, there is no need for experimental economics procedures to set up navy patrols around the Horn of Africa. Giving the green light to the competent admiralties should suffice.

That said, an economist's role is to acknowledge an interesting problem in that very area where his skills are seldom acknowledged, it seems, and so he would be delighted to be allowed to formalise the symmetries between the tactics available to victims, pirates and States in terms of models borrowed from game theory. However, the economist also has some more general comments to add.

The difference between deterrence and prevention, the reason that the military man will often instinctively silence the economist, does not actually come under the scope of cost-benefit analysis. This is because the military man has the resources available to calculate an escalation to extremes. Typically, this is not really reducible to the criteria an economist would use, since the military man's rationale is to break the other whatever the cost.

These tactics are indeed not unfamiliar to the economist. It is the underlying rationale, more than calculation of the relevant criteria, that may give his partners pause for thought. For instance, a firm may undercut prices in order to outdo its competitors. Certainly, an economist can help to make sure that such a

\footnotetext{
${ }^{6}$ Moreover, this is a theme that has been catalogued by folklorists: the devil offers to build a bridge when its construction falls behind schedule (Folktale AT 1191, Aarne and Thompson 1964).
} 
strategy is as low-risk as possible. He can also describe it, since he has the experience to understand it. The aim is to describe and prevent behaviour aggressive enough for their prospective analysis to include the risk of certain mutual destruction. That is the problem we have to weigh up. Let us now state it in somewhat more provocative terms: it is the right time, and may even seem reasonable, to say that urgent consideration must be given to one straightforward question: do we really have to go grudgingly, as it were, into the globalised economy, into one crisis after another peopled by elusive enemies? The economist has a few reminders to give in this regard.

We have just seen that there is little sense in expecting any second-rate review aimed at bringing those responsible for this or that programme before the Court of History. There would be little point, for instance, in accusing mortgage-lending banks of being insensitive to the rapidly dissuavsive difficulties experienced by borrowers in meeting repayment terms. Nonetheless, it is true that the escalating defaults on mortgage payments and the growing inevitability of sales at a loss destabilised the banking market in the end. However, this crisis does not spell the end of the world. Rather, it shows the limits of the role to which economists have too often been confined as the accountants of an ill-justified and ill-run system.

On the other hand, we shall see how increasingly urgent it is to have a process that strengthens our sensitivity to the losses incurred, but also to the sacrifices made and the many reactions of the working populations mobilised in the modern economy in the wake of the shortly-expected completion of market openness policy: the foreseeable closure of those markets. Important as it was to tempt to master the management of the internal risks of a given programme or of an economy bounded by identifiable reference points, it seems every bit as misguided to want to transplant the methods of this policy to areas which, by definition, we cannot reasonably hope to control. This widespread mistake is one that we risk walking right into today because we do not know what the impact of our activities will be in the outposts of the empire, the four corners of our world. The reason is not that we are any more deserving of scorn or censure than our predecessors, it is just that the world is on the brink of rather rapid and probably rather violent change now that with the mobilisation of Indonesia, Mexico and Brazil after India and China, we have come full circle and done the rounds of all of the major labour-force and consumer catchment areas available.

It is because globalisation will soon be complete that our insensitivity to unfair terms of trade and to the predictable, but unforeseeable, reactions of those concerned is untenable. Evading the issue is a tactic that is becoming a little more antiquated each day.

However, in this new world that we are being ushered into by rapid globalisation and its corollaries about which I will say a few words - I must say from the outset how forcibly I am reminded of Popper's reference to what the barbarian King Pyrrhus of Epirus said about strategy while at war with the Romans: " Another such victory and we ... are lost ».

For just a moment, we will try to see globalisation from the perspective of the 1970s. What I wish to do here is to perpetuate the spirit of open, realistic optimism that prevailed when the OECD's Interfutures exercise was conducted 33 years ago now. What were in substance the reasons adduced for this program?

As you will remember, the proponents of this analysis and assessment project -holding that the internal proletariat was to be successfully integrated in modern societies, thanks to a constantly growing middle class - proposed to raise the issue of the external proletariat: «more than 120 countries with rapidly growing populations, already accounting for three-quarters of humanity, to which the industrialised nations have a collective responsibility» (Albert, 2000). But trends in both capital and migration flows over recent years demonstrate that the prevalence of an attitude of insensitivity to the changes that are happening now has sharply increased among both public opinion and decision-makers. 
The insensitivity, not to say incredible hardheartedness of the past two decades has such an impact on us that we have to belabour the point, in order to make this change in ideas and attitudes more apparent. Who is so bold as to say that, over the past twenty years in a certain number of countries in Africa, there has been a decline in the number of children in school, and not just relative to the school-age population, but in absolute terms? For a generation, the dominant «Trade not Aid» motto, which promotes trade with entrepreneurs in poor countries rather than increasing up support for needy populations, has marked a retrograde trend. It seeks to extend prematurely, to countries on the farthest fringes of our economy, processes which, incidentally, our experts did not invent, but which grew out of the countries of Asia and South America: developing the local middle classes, boosting agricultural exports, freezing agrarian reforms and criticism of land redistribution. These policies have a quantified target: the sadly famous 0.7 per cent, which our governments should be earmarking for aid to the poor countries of the Third World, said by some, when it was introduced, to be a reduction compared with budgets and policies in colonial times. This is a controversy beyond the scope of this paper.

\section{Three models for managing the future}

I will now turn for a moment to contrasting descriptions that address the future. Along the way, I invite you to reconsider extrapolation and strategy procedures, two familiar approaches, which many people seem to think exhaust all the possibilities. This is true, in a way, since if they are taken as opposite extremes, however artificial this often is in practice, they do appear to cover all of the approaches between them. This is a dangerous mistake to make for one simple reason: both procedures often - so often that one may ask why - omit an approach that is nevertheless common to both of them: sensitivity. Let me explain.

First, there is extrapolation, in a way the more naturalistic of the two, as we shall see. For some people, extrapolation is the driving force of forecasting. A forecaster's job is often to extrapolate trends from the known past to a future that is assumed to be uncertain. On the timescale marked out for measurements taken for this purpose, the present is ideally represented as no more than a point, which must not distort the calculations too much.

However, the present does exist; we live in it. That is why good observers, such as Jacques Lesourne, have been keen to repeat that prospective analysis, an exercise which by its very construction is oriented towards long-term, can reduce the pressure exerted on the present by the short term. Extrapolation has been criticised for ignoring freedom, disregarding the undeniable span of the present, the uncertainties related to our imperfect knowledge, etc. These criticisms are interesting, but before addressing them, I would like to give a brief description of the other family of approaches to the future.

From more "interventionist" circles, we have actually inherited a second method of matching what we see with what we forecast. Strategy, indeed, can be described as reversing the order of the ends and the means of extrapolation procedures. What it sees and faces are the objectives that can be ascribed to the future, not the data inherited from the past. What it seeks to be able to forecast are patterns of available investment that will have to be called on in the near future if a given long-term end-point is to be attainable. The challenge that strategists agree to take up is to choose among possible futures, deploying the appropriate resources to best advantage. Hence, strategists take the opposite tack to forecasters. They endeavour to find out more about the resources of an uncertain present that can be deployed to attain a future that they profess to choose.

As we have said, treating these two theories as opposites is largely artificial: good strategists must know their way around extrapolation, while forecasters have to take strategic interactions between agents into 
account. Consequently, as I have said, those who advocate either method to the exclusion of the other need to be taught that they are complementary. That is why I wish to say a few words about one strength they have in common. Faced with the conventional opposition of the two, my comments are intended to bring certain echoes of the word sensitivity to life again. The aim of this exercise is to help the actors pay a little closer attention to context: the set of circumstances, by definition complex and underestimated, in which any change carries major consequences.

The keyword here is sensitivity to distant, complex, barely perceptible evolutions: how does one ensure that the signals sent by a world that is in the process of delivering its own future are not unduly neglected when we are busy primarily with the forecasting or monitoring tasks that our local job requires? To state the question in more direct terms: which elasticities are weak today for decision-makers and their advisers but will be critical tomorrow, and relative to which processes? What things are we not paying attention to today, more or less intentionally, that we will inevitably have to think about tomorrow?

To take a basic example, we have long counted on the low elasticity of transport demand relative to energy prices, to the point of taking this low elasticity as some sort of universal constant. If we are to survey this problem, a good questionnaire should be able to capture these potentials even before they occur. The variables to be measured and the indicators selected must be carefully calibrated so that they do not conceal what is not obvious (Prelec, 2004). While not attempting to try to teach professionals how to draft questionnaires, how many thousands of very expensive ad hoc surveys have been content with reproducing what was alleged to be true?

It must be said that the extrapolation work requires a certain strength of character. It is about putting a name to developments; that is to say, about designating areas where a relevant variable, albeit a third derivative, changes sign. Incidentally, if futurists wish to extrapolate well, they must not be slow to recognise change. For instance, how many authors religiously trotted out the theory that, since transport demand was relatively inelastic to transport costs, one could ignore ranges of values and population subgroups in which highly predictable changes in attitude were already becoming apparent? Futures analysts seem to let themselves become inured to the surprising, if negligible, speed of such changes.

Strategists are more known for their insensitivity. All they can see is the objective, people say. They are capable of steamrolling everything in their path on their march towards destiny. That is certainly not wise, but excess is the hallmark of the strategist.

If there is one thing that risk analysis in major technical projects has been able to teach us over the past few decades, it is that a total lack of sensitivity makes for good actors, in the sense understood in Diderot's Paradoxe sur le comédien : « it is extreme sensibility that makes mediocre actors; it is mediocre sensibility that makes the multitude of bad actors; and it is the absolute lack of sensibility that prepares actors who shall be sublime ». The detachment of the mad scientist contrasts with the chatty tone of the newspaper columnist.

Since extrapolation seemed to ignore the freedom to change, it is quite reasonable to want to include this freedom in forecasting: one day US consumers buy fewer four-wheel drives, for example. However, it may prove decisive, as we can perhaps see more clearly today, even if we are going through a politically and intellectually retrograde period, to look for this more essential function, which I call sensitivity, preparing freedom. We will come back to this point later. 


\section{The case for institutions}

An ill-defined policy is still a policy. A preference to have no policy is permissible, but in that case, one also has to wager on the chances of success of the «no-policy » option.

As Pascal, a mathematician who was also interested in the decision-making process, explained « ...but you must wager. You are embarked »: there is nothing clumsily interventionist about trying to understand the dynamics of an action.

The fact is that economics is not to be confined simply to drafting recommendations for an inescapable but obscure institutional outworld. Where need be, it can also study the environment that produces these institutions, as the vector through which their recommendations are requested,

As well as that, over and above the mechanisms of contractual transactions, economists are able to evaluate the impact of the statutes of institutions to which the actors belong on price-setting mechanisms: transactions are negotiated within an institutional framework that is given and liable to change.

What is an institution? Hauriou, the founder of modern institutional studies, will serve as our guide: « A little sociology leads away from the law, much sociology leads back to it ». An institution is a source of law and, at the same time, it is an actor capable of initiatives; it can more easily be described by saying what it is not. An institution is a source of standards, but is not the same as the law and not the same as a contract. A contract has value only because of the interests of the parties to it. The law assigns duties to subjects regardless of their interests. An institution carries out the duty that its mandate assigns to it.

When we speak of statutes, different information asymmetries, powers to negotiate or exercise a veto, what we are talking about are the established, stabilised components of social interactions. Should we try to ignore them? No. Classic theory allowed us to raise profound but simple questions, such as "What is the nature of the firm? ", the question raised by Coase (1937) more than half-a-century ago. If the price mechanism were the only way to ensure co-ordination among agents, why would entities such as firms exist at all? This work, which has long been regarded as a "tour de force » of neoclassical theory, was in fact an effort to take the real world into account.

The market itself is an institution, loaded with deeply ingrained historical and local characteristics. Every country lives off a capital of established customs which account in part for the diversity of policy choices that it can make.

One of Coase's fundamental ideas is worth noting: institution is not here in order to breathe a little more soul into an inhuman market. It does more than ensure a little justice and fairness. Primarily, it plays an intrinsically economic role by helping to manage the problem of transaction costs. Contracts are not free bilateral interactions sheltered from any social influence. A world with no memory would be very costly in terms of transaction prices. After all, as the Olson (1965) paradox demonstrates, the production of a public good is not necessarily always promoting the self-interest of the rational individual. We know that this paradox did not hinder critical thought, as it allowed Olson to illustrate the variable weights of individual and sometimes diverging interests according to group size, for instance, leading to his famous conclusion that small groups could be more effective than large groups in mobilizing individuals. Rousseau, in his Discourse on the Origin of Inequality (1775), paints this logically consistent model: «If a deer was to be taken, everyone saw that, in order to succeed, he must abide faithfully by his post: but if a hare happened to come within the reach of any one of them, it is not to be doubted that he pursued it without scruple, and, having seized his prey, cared very little, if by so doing he caused his companions to miss theirs. » 
The new institutional economics of Coase and North revisits this issue in depth since, in their work, not only do institutions influence actors, they are themselves created by the actors' efforts to reduce transaction costs. When a market that has become very fluid spawns relations that are improvised, aggressive and verging on violent, some of the actors will apply the institutional brakes necessary to curb the costs of such improvisation. Institutions, North says, are humanly devised constraints that structure political, economic and social action. In a situation of bounded rationality, he says, it is often rational to fall back on established procedure, available knowledge and a given apparatus; accounting for contingency like this gives economics access the world of ordinary humans.

Therefore, although transactions sometimes generate poverty or revolt, there are no grounds for lazily concluding that this is inevitable. Observation of the actors' behaviour shows that Coase's entrepreneur keeps processes that he could outsource inside the firm, because he sees certain inherent advantages in the firm/institution and in the relationships of synchronisation and subordination that it allows. 


\section{Decision theory and its history}

«Entre ma passion pour l'histoire et celle pour la modélisation mathématique, je n'avais pas à trancher. La science économique pouvait les satisfaire toutes les deux. » Lesourne, 2000, p. 189-190.

(I did not have to decide between my passion for history and my passion for mathematical modelling, economics could satisfy them both)

Being sensitive to what one risks losing, or what one is already losing, precisely because that loss was for too long considered negligible, and being capable of doing the calculations over again, is an imperative for us today and one that economists are professionally familiar with. In order to understand what is new about this imperative for a certain number of actors battling in business or in politics, I propose to give you a brief review of some recent achievements in risk theory.

Calculating damages from events subject to any given probability distribution raises problems and the formulation of those problems has seen changes over the last few decades. At this point, I propose to make a few short comments on some aspects of these developments in thinking. Decisions on resource allocation under a risky environment often obey today the theoretical model known, in modern terms, as the " expected utility» model. This section briefly reviews the history of our ideas on this subject, which we will see, I hope, are not out of place in this discussion.

The theoretical model for expected utility, outlined by the Bernoulli family in the early years of the 18th century and formalised a century ago by Von Neumann and Morgenstern, corrected classic rationalism and the optimal application of probabilities to decision-making which had prompted the correspondence between Pascal and Fermat in the mid-17th century. The latter had confined themselves to rationalising decisions solely in terms of the expected value of the benefits associated with a set of events, each of which had a given probability.

To go back to our overview and simplify matters, let us first consider the ideal case of a world without uncertainty. If the future development in the economy is certain, it is unique and the actors have no great difficulty in knowing what it is since it can be deduced unmistakably from the present state of affairs. The revenues generated by investments are known and there is therefore no risk, no risk premium, no speculation and no insurance. However, we know that not even Robinson Crusoe lived in that kind of economy. Firms, contracts, institutions and the market can only interact in a world where there is, at the very least, chance and a way of taking it into account: through risk calculations. If allowance is made for chance, then possible events and their consequences are not ruled out, even if we follow policies aimed at excluding them or dealing with them.

Let us now review a few critical steps towards these developments in allowing for the evaluation of possibilities. For the authors who were the founders of probability calculation, Huygens and Bernoulli with Pascal and Fermat, future events are unknown but not their probabilities ${ }^{7}$.

\footnotetext{
${ }^{7}$ Expected value is obviously not necessarily part of the set of observable events. Hence, in the case of an unloaded, six-sided die, the expected value is 21/6, or 3.5, a figure which does not appear on any side of the die.
} 
Does that cover everything? Do we now just have to add some detailed results into this general theory? No. A counter-example formulated by one of the active figures in the construction of probability calculations very quickly showed that rationality in these calculations could not always be recommended. The Saint Petersburg Paradox, constructed to demonstrate that although an infinite gain over the long run should, under expected value theory, prompt someone to gamble an infinite sum, observation shows understandably - that a rational gambler will avoid the extremes to which the rationalist decision leads and, in fact, will quite reasonably bet a relatively small amount. When presenting this paradox, "Bernoulli's nephew », Nicolas, noted at the beginning of the 18th century that if the expected utility of the gain was the only criterion used, as it was for the probability theorists of the 17th century, one would inevitably be recommending choices that no reasonable person would make in practice.

Bernoulli's conclusions were of even more value than his paradox. He concluded that a new concept, that of expected utility, should be introduced. He opened up a new field when he proposed that no estimation of risk could neglect the reverse problem: what is the gain required to furnish a given person a utility about which practically nothing certain can be said since it is so subject to change with circumstances. He continued "Thus, although a poor man generally obtains more utility than does a rich man from an equal gain, it is nevertheless conceivable, for example, that a rich prisoner who possesses two thousand ducats but needs two thousand ducats more to repurchase his freedom, will place a higher value on a gain of two thousand ducats than does another man who has less money than he. »

Expected utility models will therefore take account of the decision-maker's attitude by applying a utility function $U$ the sole basis of which are the decision-maker's wealth or gains. While Bernoulli's assertions have, of course, come in for criticism, the fact remains that he opened up a new world to us. In a sense, his intuitions are truer still today than when he first formulated them: for modernists at the end of the 20th century, a concave utility function would come to signify risk aversion; the steeper the curve the greater the aversion. Let me draw your attention to the extremely universal nature of this reasoning. This analysis of perceptions, i.e. the diminishing valuation of successive marginal utilities, enabled the construction of one of the first mathematical functions of valuation behaviour and the introduction of experimental procedures in numerous disciplines.

At this point, I would mention, if I may, the economic theory of diminishing returns on increasing investments or the physiological theory of perception as a function of increments in value of data perceptible to the senses. These highly diverse fields required relentless clarification in order to avoid the emergence of a risky "theory for everything ». We have now arrived at a threshold that enabled 19th century men of science to cross over into the New World of social science. Analysis of the types of attitude that actors have towards risk from the classic curve is not at all anachronistic. For a person who is less tolerant of risk than another, the utility function will be a concave transformation of the utility function of the latter. In the case of people with zero risk aversion, the utility curve will be linear while for others who are risk-seekers, the lack of aversion to risk will show as a convex utility function. 


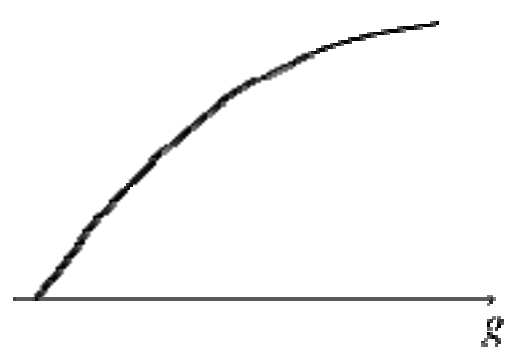

Figure 1. Utility $U$ as a concave function of gains $g$ (Bernoulli 1738).

Expected utility theory, without the shadow of a doubt, has been the dominant paradigm of decision theory since the middle of the last century. It can been said, simplifying a great deal, that until the 1980s it provided an often controversial but always accepted reference framework for prediction in the field of economics and finance, direction in the management sciences and description in the field of psychology.

Yet, from the very beginning, some very relevant - and scathing - comments had been made based, for instance, on another counter-example which proved very fruitful: the Allais Paradox. Presented to the American Economic Society in 1953, this paradox was to set a decisive limit on von Neumann's expected utility theory (Allais, 1989). I will not go into detail, here, on the discussions that have marked the past half-century, but will briefly present some simple properties of other models inspired by prospect theory as proposed by Kahneman and Tversky $(1979)^{8}$, tackling the now acknowledged impasses of expected utility theory.

This family of models is more descriptive than normative in purpose: they are an attempt to understand what decision-makers do, how they make intuitive judgements and what their choices reveal, not to propose any general or absolute optimisation criteria to them. Expected utility theory tried to reconstruct the decision-making process from the standpoint of logic, while prospect theory focused on describing the mental process of decision-making. In this latter case, emotion and, more broadly, action, are an integral part of the decision-making process. It was a genuine attempt to construct a broader-based decision theory which would set the already recognised advances by rational decision theories in their proper context, without actually contradicting them.

Let us say from the outset that the aim, according to the authors themselves, was not to give a better description of the behaviour of insurers and bankers. The models constructed by Kahneman and Tversky (1979) try at most to give an account of certain relatively simple and isolated characteristics of decisions. This severely curtails the descriptive scope that one might wish to ascribe to them in relation to the real world. Last, but not least - and this commensurately reduces the predictive power of the theory - in the real world, as Kahneman was keen to demonstrate, it often happens that people take risks because they do not know that they are taking them. Hence, one should certainly not look to prospect theory to provide direct answers to the practical questions that decision-makers ask themselves in the real world.

\footnotetext{
${ }^{8}$ The value of this theory is that it revisits several fundamental issues: for their study on aversion to ambiguity (which inclines people to gamble more willingly when the probabilities are known), Tversky and Fox (1965), following the Ellsberg Paradox (1961), mention the Treatise on probability by Keynes (1921) which was published in the same year as Knight's doctoral dissertation (1921), in which the latter paved the way for Coase and married the theory of the firm with risk theory.
} 
Numerous empirical studies conducted in recent decades have demonstrated that there are deviations from the behaviour predicted by expected utility theory. Risk aversion as exhibited by decision-makers proves to be more complex in practice; furthermore, it is related to a new aversion, the aversion to loss, and takes account of the consequences of a sequence of gains and losses.

A short introduction to probability distortion after Kahneman and Tversky may prove useful: events that have a very low probability of occurrence, close to zero, are subjectively perceived as having a higher probability (overestimation transformation), while those with a high probability of occurrence, close to one, are subjectively perceived as having a lower probability (underestimation transformation). Hence, in order to describe the behaviour of a decision-maker in the case of a lottery $(x, p)$, objective probability $p$ is replaced by a probability distortion, applying a probability transformation $w($.$) , strictly increasing over the$ interval $[0,1]$ where $w(0)=0$ and $w(1)=1$. Instead of evaluating the lottery $(x, p)$ by $p U(x)$, it is valued as $w(p) U(x)$, where $U($.$) represents the person's utility function.$

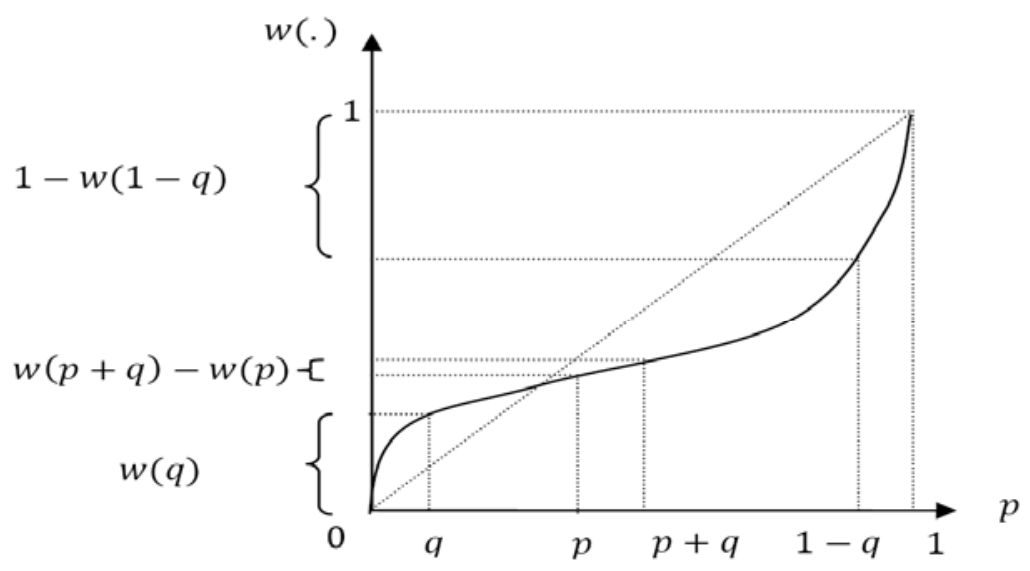

Figure 2. Probability wheigting function: subjective probabilities $w$ as a function of objective probabililties $p$ (Tversky and Kahneman 1992).

Tversky and Kahneman (1992) later extended prospect theory and found that the way in which people tended to distort the probability of an event depends on how they rank that prospect on a scale of order of preference from most to least favourable. The person then works out the cumulative probability of obtaining at least a given sum. Hence, as illustrated in the figure above, if the probability of obtaining at least 1 is actually $q=15 \%$, a person will estimate this probability as $w(q)=35 \%$, for example. Moreover, if the probability of obtaining at least 2 is actually $p+q=50 \%$, people will estimate this probability as $w(p+q)=45 \%$. The probability of obtaining between 1 and 2 will therefore be distorted from $p=35 \%$ to $w(p+q)-w(q)=10 \%$.

The curve shown above plots the transformations for risk attitudes is a case of bounded rationality, as it has been known since the seminal papers by Simon (1982). In order to plot this curve, a more complex utility function is introduced that takes other distortions related to subjective evaluation into account. First, we note an asymmetry between the perception of gains and losses: it is immediately apparent that the utility function is concave for gains and convex for losses. There is also some diminishing sensitivity: the impact of some gain variation diminishes with the distance from the reference point. Lastly, the marginal disutility of losses is greater than the marginal utility of variations of the same magnitude in gains. 


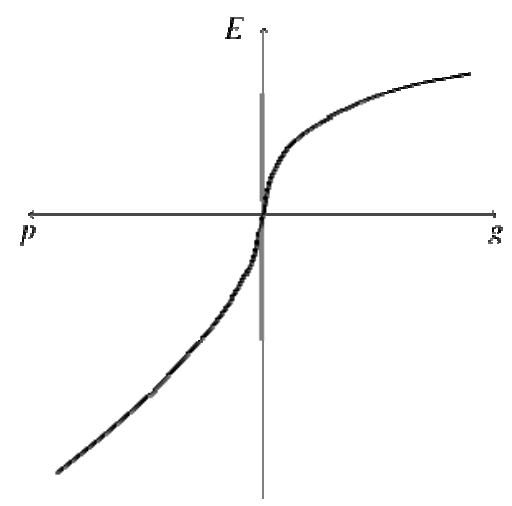

Figure 3. Transformation of gains and losses: subjective evaluation $E$ as a function of the objective income ; the regions of gains $g$ and losses $p$ are distinct (Tversky and Kahneman 1992). The reference point is here $(0,0)$.

\section{The experimental approach to risk perception: a brief overview}

At this point, I propose to make a few remarks about some aspects of the relationships between security management, risk analysis and cost-benefit analysis. Experimental psychology and economics have highlighted systematic deviations in the behaviour of people confronted with risk where numerous conventional approaches propose prediction based on expected utility theory.

These systematic deviations reflect a tendency to distort probabilities and their consequences depending on whether events are rare or frequent, since we have demonstrated that there is an asymmetric distortion between gains and losses. In real life, individual perceptions influence not only individual decisions but also the decisions of governments subject to the influence of public opinion or elections.

There are several aspects to probability distortion.

Individuals have a tendency to overestimate departures from deterministic situations (probabilities are distorted in this case). Low probabilities (rare events) are systematically overestimated. There is a fundamental difference between an event that is impossible (probability strictly nil, generally undistorted) and an event that is possible but highly improbable (which will be overestimated). Mathematically, this property is reflected by a discontinuity in the distortion function near the point of origin.

Certain probability distortions of this type have been studied by de Palma and Picard (2008) with the aid of a database of over 4000 people (using an "experimental economics" procedure run through an Internet site, http://www.RiskToleranceOnLine.com.

The types of question asked in order to highlight these probability distortions are as follows:

Which of the following two possibilities do you prefer?

o Option A, lottery (EUR 1000 , where $p=0.05$ and EUR 100 where 1- $p=0.95$.

o Option B, a sure gain of EUR 140. 
Calculations show that the Option A lottery offers a chance of winning EUR 145, an amount which is higher than the sure gain offered in Option B (EUR 140). The risk premium is therefore EUR 145 EUR $140=$ EUR 5. Generally, it is not enough to explain the choice of Option A by a person whose risk aversion has previously been estimated based on lotteries where the chance of winning was of the order of 50 per cent. This person shows an optimism bias, in that he pictures himself on the " winning side of the divide » and overestimates the probability of winning the « jackpot » of EUR 1000.

Conversely, there are low-risk situations where losses can be high. Often, we find that there is a pessimism bias which makes people overestimate low probabilities of poor performance and avoid the relevant options more than they should under expected utility theory. For instance, many travellers reacted to the events of September 2001 by avoiding air transport and using the car for long-distance travel instead. As transport by car is much more dangerous than air transport in terms of accidents per kilometre travelled, this was a case of pessimism bias: the consequences were an increase in the number of deaths.

The rejection of options which carry a risk of adverse consequences is amplified by two other phenomena. Firstly, people do not like to be disappointed, i.e. to suffer consequences that leave them less well off compared with a given point of reference. This anchor point can be conditioned by on one's past experience or future expectations. Mathematically, this is reflected in a discontinuity in the derivative of the utility function in or around the reference point. In this case, the slope to the right of the reference point is less steep than the slope to the left: people are more sensitive to a change in outcome when they incur a loss (defined in relation to the reference point) than to a change in gain of the same magnitude.

From the analysis of the data gathered via http://www.RiskToleranceOnLine.com three different patterns of attitude to risk have been found, expressed here in terms of total lottery wins.

1. Risk aversion: respondents do not like risk and are ready to settle for a smaller amount than they had hoped in order to avoid putting it at risk. The reduction they accept is the risk premium.

2. Aversion to loss: with a point of reference of EUR 100, the risk premium for a lottery where there is a possibility of loss (for example, one that offers the same probability of winning EUR 90 or EUR 110) will be higher than for a wins-only lottery (for example, one that offers the same probability of winning EUR 100 or EUR 120). The same person would be ready to pay a risk premium of EUR 5 in the first instance (deterministic win of EUR 95) but only EUR 3 in the second case (deterministic gain of EUR 107).

3. Lastly, people have a tendency to distort low probabilities of very high gains (optimism bias) and high losses (pessimism bias).

Where major risks to society are concerned, a further distortion pertains. It is related to the scale of an incident and to the fact that society seems less able to tolerate major disasters than repeated incidents, even when the total number of victims is the same in both cases. This is an aggregation bias. The figure attached shows experimental data/perception pairs for a certain number of familiar causes of death.

In other words, it seems that society as a whole would more easily tolerate a series of accidents each causing minor damage than a single accident that causes major damage, even when losses are the same: for instance, judging by the various indicators that inform policy discussions or the column inches in newspapers, 5000 road accidents each causing one death has less of an «impact » on us than five air transport accidents each causing 1000 deaths. This comparison does not mean that we should resign ourselves to abandoning risk management policies. On the contrary, it is something that more responsible risk management should think about. 


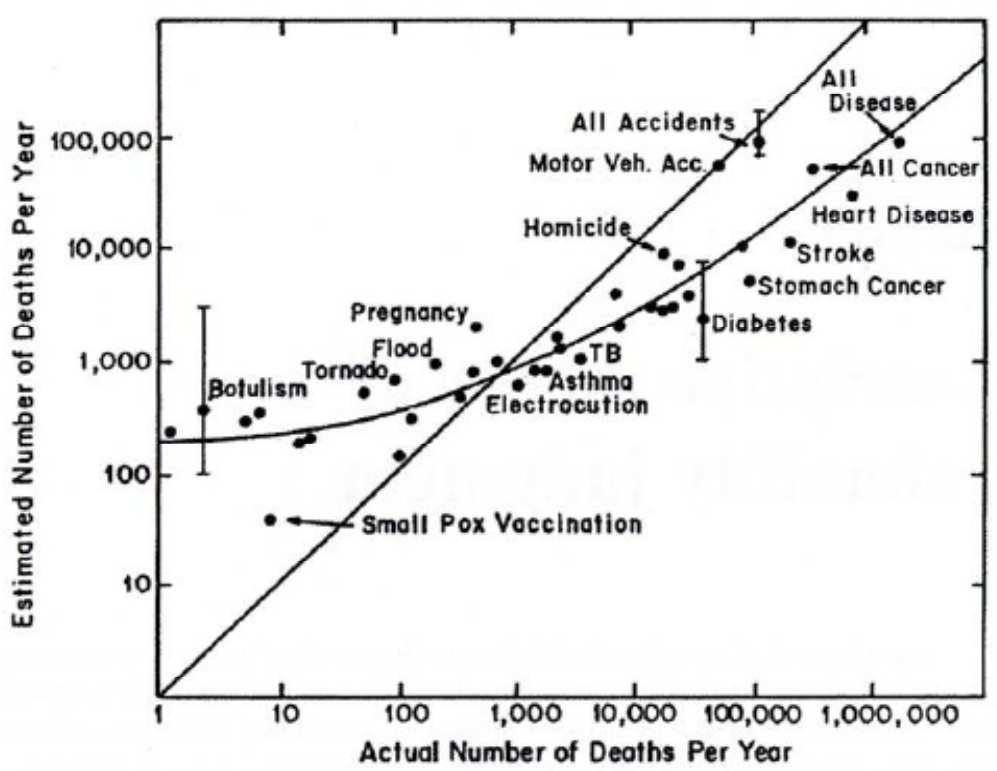

Figure 4. Déformation of deaths numbers:in abscissa, actual number of deaths per year for some sets of causes ; in ordinate, estimated number of deaths (Lichtenstein et al., 1978).

Quite obviously, these perceptions differ from a normative (expected utility theory) and descriptive (behavioural finance theories, see Thaler, 1993) perspectives. Cost-benefit analysis proposes a method for allocating public resources to choices that offer the best combination of efficiency and equity. Resource allocation is also subject to acceptability criteria for investment decisions ${ }^{9}$. We have seen that the public's perceptions are subject to perception bias and other anomalies which mean that it is far removed from the rational man whom classic economic theory viewed as taking decisions without bias and free of influence.

\footnotetext{
${ }^{9}$ This applies particularly to public goods (transport infrastructure, environment infrastructure, etc. see de Palma et al. 2005, 2007, 2008)
} 


\section{Conclusions. Any terrorist worthy of the name has something to lose}

I will close with these few pointers. While the logic of Aristotle described man as conceived by philosophy, now in a dramatic turnaround, we are attempting to gain a better understanding of real men and women. Psychology and economics have done better than follow this general trend in the scientific approach. Risk calculation is no longer a disembodied normative ideal. Today, it assesses the real-life contexts in which evaluation and decisions take place.

As regards economic transactions, it is institutions (whether Coase's firm, the marketplace of a provincial village or the IMF) that enable us to manage certain objectives that would not result spontaneously from social interactions.

Over the next few years, institutional creativity will be sorely needed. The stability provided will have to offset certain distortions in judgment and preferences, which psychologists and economists have learned to try to recognise today, now that we have moved on from simply establishing normative doctrines of rational action. Institutions allow us not to exploit the fact that the psychological attitudes of our partners can be taken into account ${ }^{10}$. They guarantee the viability of situations which, without them, could be disastrous.

In periods of great instability, it can be crucial to remain capable of seeing that negligence, hostility and incompetence are labels that we choose to cling to when we stop negotiating on the basis of partners' preferences and begin to fight with them: people who are negligent, incompetent or hostile are people we no longer negotiate with. Under these conditions, the input from economists cannot be to provide weapons for archaic rituals of execution and expulsion. Before helping to stamp out or control terrorists, before working out a theory that explains the flaws that allow us to predict, repress or explain them, economic science can help us, more simply, to continue to pay attention to the instability that threatens our own analyses and to the distortions that affect our perception of what is at stake and of the probabilities in instable transactions. Hence, economics stands poised to demonstrate that it is now a human science in its own right.

There is much evidence that any group of human beings is capable of dealing with probabilities. The prehistory of games, just like that of rituals, attests to this interest ${ }^{11}$. That is why risk - like language, tools, or kinship - can be said to be a constant of human society. This comment has relevance for more than simply theory. It has a bearing on decision-making in an unstable environment.

When groups of humans who are strangers meet, the radical instability of relationships that are neither codified nor institutionalised lead to rapid shifts in stakes that can swing from trade to war and back. A noteworthy analysis by Lévi-Strauss has provided a model for this instability ${ }^{12}$. It is this instability that institutions can channel. The risk of outbreaks of non-negotiable violence - certain of modalities of which

\footnotetext{
${ }^{10}$ We know that the Vienna School and von Mises (1940), tried to draw on the logical process of human action, praxeology, to avoid over- psychologising. A properly conducted psychological experiment cannot fail to reveal why it was rational for someone to do one thing or another under this or that set of circumstances.

${ }^{11}$ We could mention the outstanding work done by Ascher (1991), which shows how points awarded for different outcomes of a game of chance played by the Iroquois Cayuga are proportional to the probability distributions of these outcomes.

${ }^{12}$ Although this study of models was taken up again in his essay on the Nambikwara Indians and in some passages of Tristes tropiques, its first appearance was during the First World War (Lévi-Strauss, 1943). Many political studies try to describe terrorism in terms of unstable interactions, instead of pretending to reduce it to some explaining causes such as poverty, culture, etc. Let us mention here the recent work by Sageman (2004).
} 
have been given the name terrorism -- is not external to the society we live in and therefore calls for social, political and economic solutions, not for the technical calculation of prevention or repression.

A memorable anecdote from Roman antiquity relates that pirates sailing in the vicinity of Scipio's home asked if they could pay homage to the great man (Valerius Maximus, 30). Informed readers think that it was actually the victor of Carthage they wished to honour; after all, as pirates worthy of the name, they had reaped the benefits of the annihilation of the only great maritime power in the western Mediterranean. Historians shown how barbarians and pirates are invariably an integral part of the economy of the Empire that they appear to be threatening from the outside. ${ }^{13}$ That is the difficult but necessary analysis that we should preferably be capable of conducting given the extreme events that the current changes in our world are bringing about. Economics could perhaps have some suggestions on the technical problems that this change is bringing. It can most certainly set us thinking. ${ }^{13}$ This is a classical subject from Roman and Chinese studies, to mention only two empires, but one could also
mention the colossal study on international relations by Duroselle (1992). 


\section{References}

Aarne A. et St. Thompson (1964). The types of the folktale, FF communications 184, Helsinki.

Allais M. (1989). «Les lignes directrices de mon œuvre, », Conférence Nobel prononcée devant l'Académie Royale des Scicnes de Suède (9.12.1988), Annales d'économie et de statistique, nº 14.

Albert M. (2000). 'Interfuturs vingt ans après', in Décision, prospective, auto-organisation. Mélanges en l’honneur de J. Lesourne, Paris, Dunod, p. 306-317.

Ascher M. (1994). Ethnomathematics, Chapman and Hall. 1994 ; tr. fr. Mathématiques d'ailleurs, tr. fr. Seuil 1998.

Auerswald, P., Branscomb, L, La Porte, T.M. et E. O. Michel-Kerjan (2006). Seeds of Disaster, Roots of response (How Private Action Can Reduce Public Vulnerability), Cambridge University Press.

Bernoulli D. (1738). 'Specimen theoriae novae de mensura sortis', tr. fr. "Esquisse d'une théorie nouvelle de mesure du sort”, Cahiers du séminaire d'histoire des mathématiques, 6, (1985), p. 61-77 ; eng. tr. 'Exposition of a New Theory on the Measurement of Risk'. Econometrica 22, 23-36, 1954.

Coase, R. H. (1937). "The Nature of the Firm", Economica 4, pp 386-405.

de Palma, A. et E. Quinet (2005). La tarification des transports, Enjeux et défis. Economica.

de Palma, R. Lindsey et S. Proost (2007). Investment and the Use of Tax and Toll Revenues in the Transport Sector, Elsevier Science.

de Palma, A. et J.-L. Prigent (2008a). Hedging Global Environment Risks: an Option-based Portfolio Insurance, Automatica, 1519-1531.

de Palma, A. et N. Picard (2008b). “Cardinal and ordinal measure of investor's risk aversion”, Ecole Normale Supérieure de Cachan, Department of Economics and management, mimeo.

de Palma A., M. Ben-Akiva, D. Brownstone, C. Holt, T. Magnac, D. McFadden, P. Moffatt, N. Picard, K. Train, P. Wakker et J. Walker (2008c). Risk, “Uncertainty and Discrete Choice Models”, Marketing Letters, sous presse.

Diderot D. (1773). Paradoxe sur le Comédien, Gallimard 1994.

Duroselle J.B. (1992). Tout Empire périra, Armand Colin.

Ellsberg, D. (1961). "Risk, Ambiguity and the Savage Axioms," Quarterly Journal of Economics 75, 643669.

Haig A. (2003). "The promise and perils of our times », International symposium on Sino-US-Europe relations in the new century, Beijing.

Hauriou M (1925). 'La théorie de l'institution et de la fondation’, Cahiers de la Nouvelle Journée, 4, p. 245. 
Kahneman, D. et Tversky, A. (1979). 'Prospect theory: An analysis of decisions under risk', Econometrica, 47, 313-327.

Keynes, J. M. (1921). A treatise on probability, Macmillan.

Knight, F. H. (1921). Risk, Uncertainty, and Profit, University of Chicago Press 1986, voir sa these Theory of Business Profit (Cornell University, 1916).

Lesourne J. et Chr. Stoffaës (1996). La prospective stratégique d'entreprise : de la réflexion à l'action, Dunod (2ème éd. 2001).

Lesourne J. (2000). Un homme de notre siècle, Odile Jacob.

Lévi-Strauss (1943). « Guerre et commerce chez les Indiens d’Amérique du Sud », Renaissance, I, 1-2, 122-139.

Lichtenstein, S., P. Slovic, B. Fischhoff, M. Layman et B. Combs (1978). « Judged frequency of lethal Events”, Journal of Experimental Psychology: Human Learning and Memory, 4, 565.

Meusnier, N. (2005). 'Nicolas, neveu exemplaire', Journ@l électronique d'histoire des probabilités et de la statistique, 2, 1.

Olson, M. L., (1965). The Logic of Collective Action: Public Goods and the Theory of Groups, Harvard University Press.

Pascal, B. (1660). Pensées, Paris, Seuil, 1963; engl. Tr. Pensées, Dutton 1958.

Popper K. (1961). « La logique des sciences sociales », exposé pour la Société allemande de Sociologie, tr. fr. De Vienne à Francfort, La querelle allemande des sciences sociales, 1969, Complexe, 1979.

Prelec D. (2004). “A Bayesian truth serum for subjective data”, Science, 306, 5695, 462-466.

Rousseau J. J. (1755). Discours sur l'origine et les fondements de l'inégalité, Gallimard 1989.

Sageman M. (2004), Understanding Terror Networks, University of Pennsylvania Press.

Simon, H. A. (1982). Models of Bounded Rationality, MIT Press.

Stiglitz J. et L. Bilmes (2008), The Three Trillion Dollar War, Norton.

Thaler, R.H. (1993). Advances in Behavioral Finance, Russel Sage Foundation.

Tversky A. and Cr. Fox (1995). "Weighting risk and uncertainty”, Psychological Review 1995, 102, 2 , 269-283.

Tversky, A. and Kahneman, D. (1992). "Advances in prospect theory: cumulative representation of uncertainty”, Journal of Risk and Uncertainty, 5, 1992, 297-323.

Valerius Maximmus, G. (31). Faits et dits mémorables, Belles lettres, 2005. 
Viscusi K. (2003). The Risks of Terrorism, Kluwer.

Von Mises, L. (1940). Nationalökonomie. Theorie Des Handelns und Wirtschaftens, tr. angl.Human Action: A Treatise on Economic, Foundation for Economic Education, 1996.

von Neumann J. and Morgenstern O. (1944). Theory of Games and Economic Behavior, Princeton University Press. 
